\title{
PERENCANAAN PROTEKSI KEBAKARAN UNIT KOMATSU WA600-3 DENGAN FIRE SUPRESSION
}

\author{
${ }^{(1)}$ Harianto, ${ }^{(2)}$ Budi Hartadi, ${ }^{(3)}$ Firda Herlina \\ ${ }^{(1)(2)(3)}$ Prodi Teknik Mesin, Fakultas Teknik, Universitas Islam Kalimantan MAB \\ Jl. Adhiyaksa No. 2 Kayu Tangi, Banjarmasin \\ Email: hrianto93@gmail.com,akbar_mitrajaya@yahoo.com,tanyafirda@gmail.com
}

\begin{abstract}
ABSTRAK
Pada aktivitas pertambangan tidak luput dari jam operasional yang tinggi di daerah batubara dan suhu di sekitar mencapai $34^{\circ}$ celsius yang berpotensi menyebabkan kebakaran pada unit komatsu WA600-3 (Wheel Loader). WA600-3 beroperasi di stock pile batubara menyebabkan panas berlebih (overheat) karena suhu di sekitar stock pile ataupun panas dari kebocoran sistem hidrolik yang menyebabkan menempelnya fine coal yang menyebabkan kebakaran. Penambahan proteksi kebakaran fire supression tipe LOP (Lose Of Pressure) dapat meminimalkan kerusakan dan kerugian pada saat terjadi kebakaran di PT. Kalimantan Prima Persada site Rantau. Sistem ini sangat efektif untuk mencegah unit terbakar karena aktif dengan suhu kerja $\left(160-180^{\circ}\right.$ Celsius $)$ pada detection tubing saat terjadi kebakaran dan juga bisa di aktifkan secara manual lewat knob internal actuator atau external actuator.
\end{abstract}

Kata Kunci : Kebakaran, Fire supression

\section{PENDAHULUAN}

Seiring perkembangan zaman dan ketatnya persaingan dalam dunia usaha pertambangan batubara, efisiensi dan penekanan pengeluaran keuangan sangat penting untuk menunjang produktivitas unit alat-alat berat dalam menjalankan kegiatan perusahaan. Perawatan dan perbaikan tidak luput dari kegiatan sehari-hari yang dilakukan di ruang lingkup kegiatan usaha pertambangan batubara. Dimana salah satu alat-alat berat yang ada di perusahaan PT Kalimantan Prima Persada jobsite Rantau adalah Wheel Loader (WA6003). Penggunaan WA600-3 dilakukan di stock pile batubara untuk memuat batubara yang telah dihaluskan oleh crusher (penggilingan batubara) ke dump truck (DT) untuk di angkut menuju ke port (pelabuhan) agar batubara dapat dikirim ke costumer.

Tetapi, WA600-3 ini mengalami perubahan temperatur pada unit karena unit beroperasi di stock pile batubara dengan ambient temperatur lebih dari 35 derajat celcius membuat unit WA600-3 berpotensi mengalami kebakaran.

Melakukan pencucian unit setiap hari dan salah satu cara untuk mengatasi apabila terjadi kebakaran pada WA600-3 di ruang lingkup perusahaan PT. Kalimanta Prima Persada jobsite Rantau dilakukan penambahan alat proteksi kebakaran sehingga saya tertarik untuk mengambil judul skripsi ini adalah " Perencanaan Proteksi Kebakaran Unit Komatsu WA600-3 Dengan Fire Supression".

\section{METODE PENELITIAN}

Pada penelitian skripsi ini adalah dilakukan pada salah satu alat berat yang sering mengalami kebocoran, panas yang berlebih (overheat), beroperasi di tempat batubara yang dapat menyebabkan kebakaran yaitu pada WA600-3. 
p-ISSN 2502-4922,e-ISSN 2615-0867

WA600-3 adalah sebuah alat berat yang berfungsi sebagai traktor dengan roda karet yang dilengkapi dengan sebuah perlengkapan kerja yaitu bucket yang berfungsi untuk menggali (digging), membawa (carrying) dan memuat (loading). Wheel loader sangat efesien untuk bekerja di daerah kering, rata dan kokoh terutama juga dituntut agar kerusakan landasan kerja minimal dengan mobilitas kerja yang tinggi. Wheel loader memiliki bucket yang cukup besar dibanding dengan hydraulic excavator sehingga dalam kondisi tertentu, wheel loader dapat bekerja dengan produktivitas yang sangat tinggi.

Karena WA600-3 beroperasi di stock pile batubara menyebabkan panas berlebih, baik dari ambient temperature ataupun panas dari sistem hidrolik WA600-3 tersebut yang menyebabkan kebocoran sehingga fine coal yang berada di sekitar alat tersebut melekat pada oli dan dapat menyebabkan kebakaran pada WA600-3.

\section{Diagram Alir}

Tahapan-tahapan penelitian yang dilakukan saat pemasangan dan perawatan fire supression unit WA6003 adalah sebagai berikut :

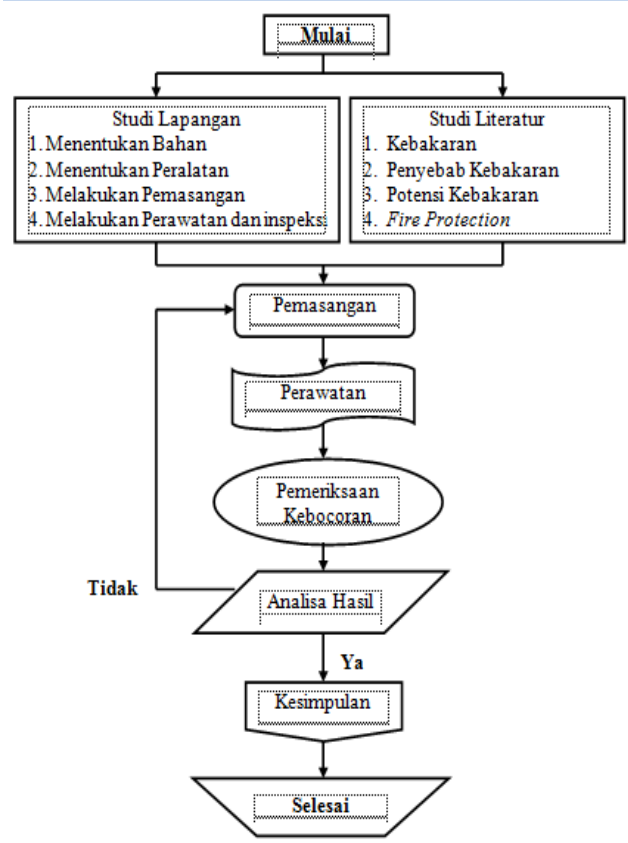

\section{HASIL DAN PEMBAHASAN}

Wiring Harness Saat Terjadi Kebakaran

Adapun wiring harness yang aktif saat terjadi kebakaran adalah sebagai berikut :

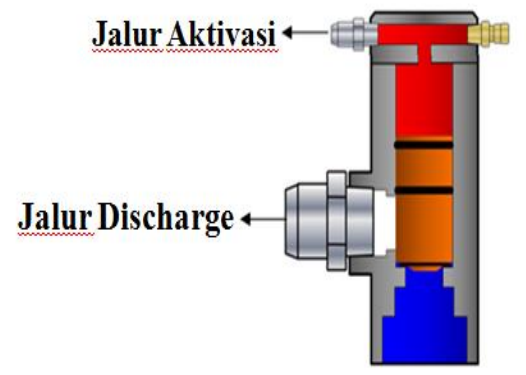

\section{Gambar 4.6 Cylinder Valve LOP Normal (Sumber : Modul Chubb PEFS)}

Pada saat tekanan pada jalur aktivasi dan tekanan di dalam feed cylinder sama $(1350 \mathrm{kPa})$ maka piston akan menutupi jalur discharge agar foam tidak menyembur.



\section{Gambar 4.7 Cylinder Valve LOP Aktif} (Sumber : Modul Chubb PEFS)

Pada saat tekanan di jalur aktivasi turun atau hilang karena putusnya detection tubing karena panas atau manual actuator di aktifkan, maka piston akan bergerak ke atas karena tekanan dari feed cylinder lebih tinggi dari tekanan di jalur aktivasi dan dapat mendorong piston, menyebabkan foam keluar menuju jalur discharge line dan di semprotkan oleh nozzle ke area yang di tentukan saat pemasangan. 


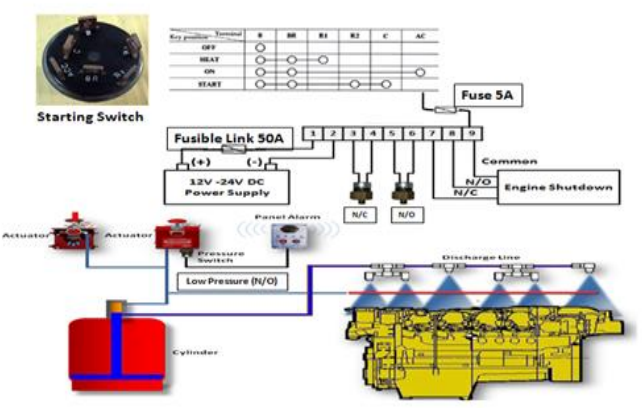

Gambar 4.8 Aktivasi Manual External Actuator Release

(Sumber : Modul Chubb PEFS)

Adapun kajian teknis penyemprotan fluida saat terjadi kebakaran dengan gaya yang di butuhkan cylinder fire supression adalah sebagai berikut :

Diketahui : Total Volume Cylinder

$\left(\mathrm{V}_{\text {Tabung }}\right)=45$ Litter $=4500 \mathrm{Cm}^{3}$

Tinggi tabung Cylinder $(\mathrm{t})=55 \mathrm{Cm}$

Tekanan di Cylinder $(\mathrm{P})=1350 \mathrm{kPa}=$ $13,76 \mathrm{Kg} / \mathrm{Cm}^{2}$

Ditanyakan : Gaya (F) optimal yang di butuhkan untuk penyemprotan fluida fire supression

$$
\begin{aligned}
\mathbf{V}_{\text {Tabung }} & =\pi \mathrm{X} \mathrm{r}^{2} \mathrm{Xt} \\
4500 \mathrm{Cm}^{3} & =3,14 \mathrm{X} \mathrm{r}^{2} \mathrm{X} 55 \mathrm{Cm} \\
\mathrm{r}^{2} & =4500 / 172,7=26,05 \mathrm{Cm}^{2} \\
\mathbf{r} & =\sqrt{2} 6,05=5,124 \mathrm{Cm}
\end{aligned}
$$

Total Volume Solution (80\%)

$\mathbf{T}_{\text {Foam }}=45$ X $80 / 100=36$ Litter

Air $(94 \%)=36$ X $94 / 100=33,84$ Litter $\operatorname{AFFF}(6 \%)=36 \times 6 / 100=2,16$ Litter Nitrogen di dalam Cylinder $(20 \%)=$ $13,76 \mathrm{Kg} / \mathrm{Cm}^{2}$

$$
\begin{aligned}
& \text { Luas (A) Tabung Cylinder fire } \\
& \text { supression LOP } \\
& \begin{array}{ll}
\mathrm{A} & =2 \mathrm{X} \pi \mathrm{XrX}(\mathrm{t}+\mathrm{r}) \\
& =2 \times 3,14 \times 5,124 \times(55+5,124) \\
& =1934,71 \mathrm{Cm}^{2}
\end{array}
\end{aligned}
$$

Gaya $(\mathrm{F})=\mathrm{P}$ X A

$$
=13,76 \mathrm{Kg} / \mathrm{Cm}^{2} \mathrm{X} 1934,71
$$

$\mathrm{Cm}$

$$
\begin{aligned}
& =26.621,6 \mathrm{Kg} \\
& =26,62 \mathrm{Ton}
\end{aligned}
$$

Jadi, Gaya yang di butuhkan untuk menyemburkan fluida fire supression untuk memadamkan api saat terjadi kebakaran adalah 26,62 Ton.

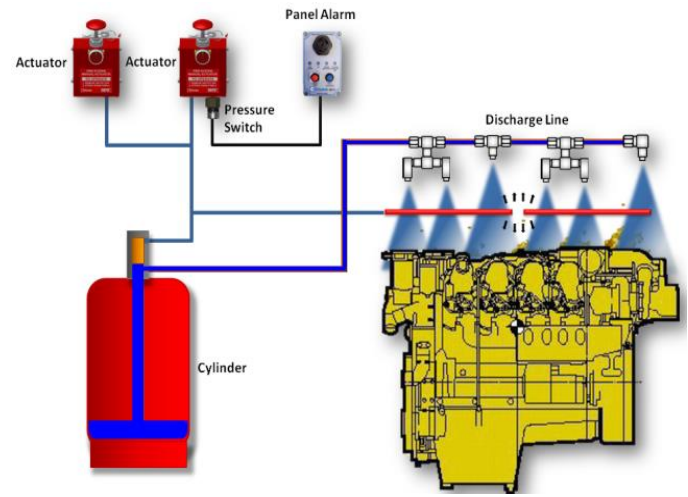

Gambar 4.9 Aktivasi Detection Tubing

Release

(Sumber : Modul Chubb PEFS)

\section{KESIMPULAN}

Dari hasil penelitian yang telah dilakukan tentang fire supression unit WA600-3 dapat ditarik kesimpulan sebagai berikut :

1. Saat terjadi kebakaran pada unit, voltage dari internal actuator atau external actuator mengirim sinyal ke monitor panel untuk mengaktifkan buzzer, mematikan engine dengan waktu yang sudah di atur sekitar 3 menit agar foam solution fire supression benar-benar habis untuk memadamkan api.

2. Saat terjadi kebakaran, tekanan di jalur aktivasi turun (kurang dari 1350 $\mathrm{kPa})$ karena putusnya detection tubing akibat panas $\left(160-180^{\circ}\right.$ Celsius) atau gesekan maka piston akan bergerak ke atas karena tekanan daari feed cylinder lebih tinggi dari tekanan di jalur aktivasi menyebabkan foam keluar menuju jalur discharge line dan di semprotkan oleh nozzle ke area yang di tentukan saat pemasangan seperti engine dan transmisi untuk memadamkan api saat terjadi kebakaran. 


\section{REFERENSI}

[1] SPS Departement 2010, CHUBB PEFS Fire Supression System ROP \& LOP Systems, PT. Partsindo Servicatama, Jalan Mulawarman Komplek Kota Hijau Ruko No. 1819, Balikpapan 76115.

[2] UT School 2008, Safety Basic Competency I Modul Siswa, PT. United Tractor, Jalan Raya Bekasi Km. 22 Cakung, Jakarta Timur 13910.

[3] UT School 2008, Hydraulic System I Modul Siswa, PT. United Tractor, Jalan Raya Bekasi Km. 22 Cakung, Jakarta Timur 13910.

[4] Institut Teknologi Sepuluh Nopember (ITS) Arif Bagus Faisal Darma,Widodo Wawan Aries,2014,Evaluasi fire protectin system pada fuel supply system, utility work menggunakan software pipe flow expert (Study kasus PT. Pertamina DPPU Juanda).

[5] http://www.digilib.its.ac.id/ITS-

paper-21121150007101/35969

diakses jam 22;11 WITA, tanggal 18 Mei 2018.

[6] Sekolah Tinggi Teknologi Bontang Zain Abdul,2016,Rancang bangun sistem proteksi kebakaran menggunakan smoke dan head detector.

[7] https://docplayer.info/83511814-

Rancang-bangun-sistem-proteksi-

kebakaran-menggunakan-smokeand-heat-detector.html\# diakses jam 22;19 WITA, tanggal 18 Mei 2018.

[8] Universitas Mercu Buana Putri Rahesa Dwi,2017,Perencanaan dan analisa sistem sprinkler otomatis dan kebutuhan air pemadam fire fighting hotel XX. http://publikasi.mercubuana.ac.id/ind ex.php/jtm/article/view/1199 diakses jam 22;26 WITA, tanggal 18 Mei 2018.

[9] Universitas Muhammadiyah Jakarta Haramain Muhammad Al,Effendi
Riki,Irianto Febri,2017,Perancangan sistem pemadam kebakaran pada perkantoran dan pabrik label makanan PT XYZ dengan luas bangunan $1125 \mathrm{M}^{2}$.

[10] https://www.scribd.com/documen t/380964632/2105-4880-1-PB diakses jam 22;38 WITA, tanggal 18 Mei 2018.

[11] Universitas Syiah Kuala Rizkia Rika Sri,Sara Ira Devi,Gapy Mansur,2017,Sistem deteksi kebakaran pada gedung berbasis Programmable Logic Controller (PLC). 